\title{
Integrating Multiple and Focused Strategies for Improving Reading Comprehension and L2 Lexical Development of Iranian Intermediate EFL Learners
}

\author{
Mehdi Nasri (Corresponding author) \\ Department of English, Khorasgan (Isfahan) Branch, Islamic Azad University, Isfahan, Iran \\ E-mail: me_nasri@yahoo.com \\ Reza Biria \\ Khorasgan (Isfahan) Branch, Islamic Azad University, Isfahan, Iran
}

Received: 15-08-2016

Published: 02-01-2017
Accepted: 10-10-2016

doi:10.7575/aiac.ijalel.v.6n.1p.311
Advance Access Published: November 2016

URL: http://dx.doi.org/10.7575/aiac.ijalel.v.6n.1p.311

\begin{abstract}
Effective reading is essential for success in learning a foreign language. EFL learners, therefore, need to master a number of reading strategies to be able to comprehend text information. Strategic reading research has already evidenced the possibility of teaching comprehension strategies to enhance learner' comprehension and metacognitive abilities. Further research is needed though to examine the procedures or methodologies through which the approach can be applied. This pretest-posttest quasi-experimental article aimed, firstly, to compare the effects of the two widespread methods of explicit teaching of comprehension strategies (focused vs. multiple) on EFL learner' reading comprehension and lexical development and, secondly, to explore whether or not integration of fixed and multiple instructional techniques significantly improved intermediate EFL learners reading comprehension ability and lexical knowledge. To this end, four intact classes including 69 intermediate EFL learners in a language center in Isfahan were randomly assigned to one control and three experimental groups. The groups received the same amount of instruction, however differently, three receiving focused, multiple, and integrated strategy interventions respectively and the other receiving conventional reading-based instruction. The results revealed that while receiving focused strategy intervention did not offer a statistically significant advantage over the typical classroom setting, benefiting from multiple strategy intervention significantly improved the learners' ability in reading comprehension. Moreover, the results asserted the efficacy of integrated strategy instruction in improving both reading comprehension and lexical development among Iranian intermediate EFL learners.
\end{abstract}

Keywords: Focused strategy instruction, Lexical development, Multiple strategy instruction, Reading comprehension

\section{Introduction}

Indubitably, reading plays a pivotal role in language learning and is an essential skill for successful functioning of EFL learners in the tertiary level of education. Yee (2010) believes that the ability to read aids readers feel confident when reading course books written in English. In point of fact, this allows them to feel successful in accessing information from the targeted sources used in educational contexts. The inability to read, on the other hand, can lead to a disturbing sense of disengagement and uselessness because it can adversely affect the leaning outcomes enormously.

Asserting the multivarious roles of reading in foreign language academic contexts, Goldenberg (2011) maintains that "comprehension" is very often the main objective of the reading process and everything else is simply a means to this end. According to McNamara (2007), comprehension is the ability to go beyond the words, to understand the ideas in a text and the relationships that exist between those ideas.

Teaching reading in a foreign language, therefore, can be considered a delicate job in that teachers need to understand the nature of reading and teaching methodology on the one hand, and the nature of learners and the context in which teaching of reading takes place, on the other hand (Phakiti, 2006). Effective teachers, those who beat the odds in preventing student failure, combine direct, explicit instruction of strategies with other teaching approaches in order to embed the activity within what is called literacy development (Graves, 2004; Langer, 2002).

Within such perspectivization, reading comprehension is viewed as an extraordinary achievement in which a number of interacting levels and components need to be mastered (Graesser, 2007; Shang, 2010). The most commonly accepted way for researchers to explain the above components is to identify the key abilities and skills that allow reading comprehension to emerge.

One of these significant components which greatly influences the reading process is said to be the lexical knowledge. Lexical knowledge is a multidimensional and complex construct involving numerous types of word knowledge such as 
meaning, word form, collocation, and register (Read, 2000; Nation, 2001; Far, 2006). In other words, lexis is the building block of language and language is the core in the process of attaining literacy competency (Graves, 2009). Alternatively, words are a potent predictor of various indicators of verbal ability (Sternberg, 1987) and reading comprehension across different languages and cultures (Schmitt, 2000; Grabe, 2009).

Not surprisingly, vocabulary development is a considerably complex process due to the size of the potential lexicon and the multifaceted nature of vocabulary knowledge, because the processes by which learners acquire a great deal information about a particular word gradually develops over a long period of time. Such development in both L1 and L2 occurs as learners attempt to comprehend new words they hear or read in various contexts (Krashen, 1989). Therefore, vocabulary development can expand in different ways when the learners encounter various contexts of reading, listening, and oral conversation (Nagy, Herman \& Anderson, 1985; Sternberg, 1987).

As such, the fields of pedagogy and reading have profoundly focused on strategies, and strategies have been given an important role in reading behavior discussions. Expert readers apply a wide variety of comprehension strategies, i.e., routines and procedures to comprehend what is read more effectively (Kazemi, Hosseini, \& Kohandani, 2013). Reading comprehension strategies can be defined as mental operations which are used by readers when they read a text and try to understand it effectively (Duke\& Pearson, 2002). In fact, reading strategies reveal how readers conceive a task, what textual cues they attend to, how they make sense of what they read, and what they do when they do not understand specific texts. Notably, reading strategies range from simple fix-up strategies such as simply rereading difficult segments and guessing the meaning of unknown words from the context, to more comprehensive strategies like summarizing and relating what is being read to the reader's background knowledge.

In addition, it is often stated that many learners may become expert readers if they are explicitly taught effective strategies and trained to check and monitor their comprehension while reading a particular text (e.g., Swanson, 2001; Janzen, 2003; Biancarosa \& Snow, 2006; Pressley, 2006; McNamara, 2007). Explicit instruction is intended to give students complete awareness that reading is an active process and that comprehension-fostering and monitoring activities are important. In strategic reading instruction, which is now fully supported by research as a means of helping students to become proficient readers, strategy use is integrated with the process of reading for meaning, and students are helped to apply strategies to increase their comprehension of text meaning (Janzen, 2003).

Due to the fact that reading strategies do not work in isolation and overlap each other (Roe, 2008, pp. 87-89), the present study aimed to focus on a set of essential strategies which can assist readers to fathom out the meaning intended by the author of the text. Therefore, the study considered seven reading strategies which had a considerable bearing on reading in EFL contexts. Consequently, two strategies (i.e. Questioning, Inferencing) were utilized for the Focused strategy intervention, while seven strategies (i.e. Making Connection, Predicting, Questioning, Inferencing, Monitoring, Visualizing, and Summarizing) were used for multiple strategy Intervention. More specifically stated, the focused strategy instruction concentrates on teaching individual strategies at a time by asking learners to exploit them individually for struggling to comprehend text meaning. As Nokes and Dole (2004) suggest, this type of instruction guards can bring about an overwhelming influence on students while reading a text. A noteworthy feature of this type of instruction would be providing varied opportunities to develop expertise with a particular strategy for decoding a given text.

By contrast, it is often suggested that reading different types of texts requires the use of different reading strategies and approaches and it is emphasized that a combination of strategies; namely, multiple strategy instruction, can be effective in enhancing the rate at which texts are decoded by the readers. The National Reading Panel emphasized that using the combination of effective comprehension strategies that provide specific instructions for developing and retaining comprehension skills, with intermittent feedback, has been found to improve reading comprehension across all ages, specifically those affected by mental disabilities. (National Reading Panel, 2000)

It has been found that less able comprehenders usually focus more on word accuracy rather than comprehension monitoring and generally have underdeveloped metacognition skills (Nation \& Norbury, 2005). Students with poor comprehension fail to make inferences and integrate text information. In point of fact, they tend to read superficially and are less likely to participate in constructive processes of learning and are unsure of when to apply their prior knowledge during reading (Cain \& Oakhill, 1999). Research has shown that sources of comprehension problems are independent from decoding (Williams, 2005). Alternatively, concerned researchers have identified students who cannot comprehend the text they are reading effectively in spite of successful decoding (Caccamise \& Snyder, 2005; Duke, Pressley \& Hilden, 2004).

It is interesting to note that learners who struggle with comprehension possess inefficient strategies because they do not know how to make use of them effectively in decoding meaning of the texts they encounter. They are usually unaware of what good comprehenders do and need to be shown how and when to apply the required strategies for deciphering the meaning intended by the text writer. Notably, providing students with explicit instruction in comprehension strategies can be a crucial approach by which the targeted students learn to overcome difficulties in understanding texts (Graham \& Bellert, 2004). Explicit instruction of reading strategies enhances learners' self-regulatory tactics which in turn escalates the likelihood of success in reading comprehension (Manset-Williamson \& Nelson, 2005). As learners become more confident of their comprehension, they require less support from the teacher (Duke \& Pearson, 2002). 
The number of empirical studies researching reading strategies has been on the rise. Most of reading comprehension studies have demonstrated that explicit teaching of reading strategies to EFL learners is important in enhancing proficient readers and increasing their reading comprehension. In this view, teachers should guide students to use strategies to comprehend the meaning fabricated by the author (Brown, 1981; Baker \& Brown, 1984; Grabe, 2002; Biancarosa \& Snow, 2006; Van Keer \& Verhaeghe, 2005). The following section deals with almost recent empirical studies on multiple reading comprehension strategies in EFL settings including the studies conducted in Iran.

The findings of the study indicated that reading comprehension strategies are teachable in early elementary grades and the learners are best promoted by using instructional programs that include explicit teaching of multiple strategy use with metacognitive components.

In an interesting study, Cubukcu (2008) conducted a study to examine whether explicit instruction of third-year Turkish university students on metacognitive awareness improves reading comprehension. The findings revealed that systematic direct instruction of metacognitive language learning strategies could develop reading comprehension. Fan (2009) also found out how metacognitive strategies such as think-aloud, text-structure, and summarization could be employed most effectively by Taiwanese EFL university students to improve their reading comprehension. To this end, 143 university students took part in the study. The results of the study indicated that the experimental group who were engaged in metacognitive strategy use had better gains in reading comprehension than those in the control group.

In another study, Yee (2010) investigated the role of Focused Strategy Intervention (FSI) and Multiple Strategy Intervention (MSI) in reading improvement of struggling adolescent students (i.e. students with reading disabilities and low achievers). Yee's study sought to explore the most effective type of intervention. In this regard, The FSI group were taught and practiced just two reading comprehension strategies (i.e. Questioning and Inferencing), whereas participants in the MSI group were taught six reading comprehension strategies (i.e. Setting a purpose, Making connections, Visualization, Questioning, and Inferencing). The results indicated that participants in the MSI group demonstrated significant improvement on reading comprehension especially in the area of decoding and fluency compared to the learners in the FSI group.

In a similar study, Aghaie and Zhang (2012) investigated the influence of explicit teaching of cognitive and metacognitive reading strategies on EFL university students' reading performance and improvement in Iran. After four months of strategy instruction, the experimental group achieved significantly better results compared to the control group supporting the contributory role of explicit instruction of multiple strategies in learners' reading comprehension enhancement.

In a different study, DeBoer (2003) tried to evaluate the influences of explicit teaching on cognitive/metacognitive reading comprehension strategies concerning reading comprehension achievement as well as to indicate the most effective and practical instructional model for teaching reading comprehension strategies to elementary students. To achieve this goal, explicit instruction of the four strategies (i.e. predicting, questioning, summarizing, and clarifying) were modeled for students using a think-aloud strategy. The findings indicated that reading comprehension strategies can be applied to elementary levels satisfactorily.

Similarly, Arpacioğlu (2007) investigated whether the instruction of combined strategies improved reading comprehension of upper-intermediate EFL learners at Ankara University.

The reading strategies considered for the study were as follows: Overviewing the text, understanding the relationship in the text, questioning the text, recalling background information, Predicting the subsequent information in the text, Identifying cohesive elements and discourse markers, Guessing about the meaning of unknown words using clues from the text, Skipping unimportant details, Using background knowledge for prediction, Confirming and disconfirming predictions, Setting a purpose for reading, Summarizing with own words, and Evaluating the text.

The results reported by Arpacioğlu revealed that combined reading strategy instruction had a significant effect on upper-intermediate EFL students' reading comprehension improvement in comparison with single focused strategy instruction.

In this regard, The FSI group received and practiced just two reading comprehension strategies (i.e. Questioning and Inferencing), whereas participants in the MSI group were taught six reading comprehension strategies (i.e. Setting a purpose, Making connections, Visualization, Questioning, and Inferencing). The results indicated that participants in the MSI group demonstrated significant improvement on reading comprehension especially in the area of decoding and fluency compared to those in the FSI group.

On this basis, what makes the present study different from other similar studies is its focus on hybridizing both FSI and MSI within the same treatment context because most researchers had in fact checked and focused on multiple instructional strategies separately.

\subsection{Research Questions}

This study sought to answer the following questions:

Q01: Does receiving the two instructional techniques (focused vs. multiple) of teaching comprehension strategies significantly improve Iranian intermediate EFL learners' reading comprehension?

Q02: What is the impact of Integrating Multiple and Focused instructional techniques on Iranian intermediate EFL learners' reading comprehension? 
Q03: Does receiving the two instructional techniques (focused vs. multiple) of teaching comprehension strategies significantly improve Iranian intermediate EFL learners' L2 lexical development?

Q04: What is the impact of Integrating Multiple and Focused instructional techniques on Iranian intermediate EFL learners' L2 lexical development?

\subsection{Research Hypotheses}

Based on the above research questions, the following hypotheses were formulated:

$\mathbf{H}_{01}$ : Receiving the two instructional techniques (focused vs. multiple) of teaching comprehension strategies does not significantly improve Iranian intermediate EFL learners' reading comprehension.

$\mathbf{H}_{02}$ : Integrating multiple and focused instruction of comprehension strategies does not have any significant effects on Iranian intermediate EFL learners' reading comprehension.

Ho3: Receiving the two instructional techniques (focused vs. multiple) of teaching comprehension strategies does not significantly improve Iranian intermediate EFL learners' L2 lexical development.

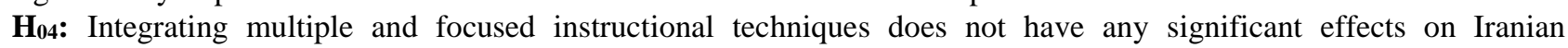
intermediate EFL learners' L2 lexical development.

\section{Methodology}

As many as 69 male and female ( 31 male and 38 female) EFL learners from a language academy in Isfahan participated in the current quasi-experimental (control-group, pretest-posttest) study. The participants' English proficiency was estimated to be of intermediate level and their age ranged from 19 to $25(M=21, S D=2.79)$. All the participants had Persian as their L1 and none of them had lived in an English speaking country before and had no opportunity to speak English outside the classroom context. The four classes were randomly assigned into one control and three experimental groups:

1) The first class, containing 16 learners, were assigned to the first experimental group. This group was labeled as the focused strategy instruction group (FSIG) and was supposed to receive focused instructional techniques;

2) The second class; namely, the multiple strategy instruction group (MSIG), consisted of 18 learners who were supposed to receive instruction on multiple comprehension strategies;

3) The third class with 19 learners received instruction through hybridization of FSIG and MSIG at the same time;

4) The fourth class with 16 learners were assigned to the control group and received no explicit teaching of reading comprehension strategies, but were taught by a traditional reading method.

\subsection{Instruments and Materials}

The instruments employed in the current study included a quick placement test (QPT) to check the participants' level of language proficiency and two different but equivalent versions of TOEFL reading comprehension test serving as the pretest and posttest to examine the participants' reading comprehension ability as well as their knowledge of English lexicon before and after the treatment.

The instructional material was "Select Readings, Intermediate", written by Lee and Gunderson (2000). The book provides learners of English with high-interest reading passages from authentic sources that act as springboards into reading comprehension activities, reading skills development, vocabulary building, grammatical analysis and practice, and thought-provoking discussion and writing. The book included 14 chapters representing a wide range of genres.

The content validity of the test was approved by the appraisal of two experts in the field of EFL teaching in Khorasgan University. The reliability of the tests was established using Kuder-Richardson 21 (KR21) approach. The estimated coefficients $(0.865$ for the pretest and .874 for the posttest), indicated a satisfactory degree of internal consistency for the developed tests.

\subsection{Procedures}

The treatment phase included several stages. First, in a debriefing session, the teachers were briefed on the particulars of strategic reading. Second, in a two-session preparatory stage, the teachers were provided with a set of teaching ideas to support the teaching process of comprehension strategies during the course (see appendix D). The teaching ideas were extracted from two key recommended texts that have been identified as a relevant source for ideas supporting the explicit teaching of comprehension strategies; namely, Guided Comprehension in Grades 3-8, written by McLaughlin, and Allen (2009) and Revisit, Reflect, Retell by Hoyt (2009).

Afterwards, the participants of the four classes enrolled in a complementary reading course and met twice a week for one and a half hours (90 minutes) each session. All groups received 15 sessions of treatment over the whole spring semester of the institute. Prior to the course, the reading comprehension pretest was administered to specify the relative knowledge of the participants on English reading and words prior to the treatment. All the three experimental groups received explicit instruction on reading comprehension strategies implementing the following five successive steps.

In focused strategy instruction group (FSIG), every fourteen units of the course-book was taught focusing on a couple of reading strategies; namely, questioning and inferencing. The strategies were introduced to the participants in the FSIG allocating the first 60 minutes of the first session to implement the five-step instructional process mentioned above. Throughout the remaining sessions, the students had multiple, varied opportunities to develop expertise with the particular strategies. 
Students were given different activities, outlined by the researcher prior to the course, to facilitate the comprehension process. In every sessions of the course, after a few minutes of individual practice to decode and comprehend the passages, the students were randomly asked to give a summary about how they exploited the strategies to discover the text meaning to the class. Asking questions appears to be a necessary precursor to inferencing. It stands to reason that gaps in the text cannot be filled unless they have been identified through a process of question generation.

The multiple strategy intervention group (MSIG) began the course allocating two complete sessions to teach all the seven main comprehension strategies; namely, making connection, predicting, questioning, inferencing, monitoring, visualizing, and summarizing. All the strategies were thought explicitly following the same five-step process of teaching comprehension strategies mentioned above. This group had the opportunity to discuss every single unit of the textbook exploiting a combination of the mentioned strategies while doing various activities.

In the integrated strategy intervention group (ISIG), the first session began receiving a total of 30 minutes of explicit instruction in making connection as the first reading comprehension strategy employing the above mentioned five-step process. The remaining time of the first session as well as the subsequent session were used to exploit the strategy while teaching the first chapter of the book. At the beginning of the third session, the second strategy called predicting was introduced and the next chapter was taught asking the learners to employ both strategies (making connection and predicting) while reading the passage. The process of introducing and teaching a new strategy was continued every session until all the seven main strategies were taught and exploited to decode the passages' meaning.

As each strategy was introduced, students were encouraged to coordinate its use with the strategies that had already been studied. During the remaining sessions (six sessions) the teacher asked the students to use a combination of all main strategies to comprehend the passages while teaching the remaining chapters of the book (six chapters).

The participants in the control group received no strategic training (explicit instruction of reading comprehension strategies) but benefited from a conventional method of reading instruction.

\section{Results}

Finally, the TOEFL reading comprehension posttest, examined all the participants' reading comprehension ability as well as their lexical knowledge at the end of the course. Table 1 displays the descriptive statistics of the pretest and posttest reading comprehension scores in all four groups of the study.

Table 1. Descriptive Statistics of Reading Comprehension Scores

\begin{tabular}{lllllllllc}
\hline \multirow{2}{*}{ Group } & Variable & $N$ & Range & Min & Max & Mean & $\begin{array}{l}\text { Std. } \\
\text { Deviation }\end{array}$ & Skewness & Kurtosis \\
\hline \multirow{2}{*}{ FSIG } & Pretest & 16 & 14 & 11 & 25 & 18.69 & 4.498 & -.168 & -1.209 \\
& Posttest & 16 & 14 & 14 & 28 & 21.31 & 4.600 & -.201 & -1.307 \\
\hline \multirow{2}{*}{ MSIG } & Pretest & 18 & 15 & 9 & 24 & 18.06 & 4.277 & -.764 & -.082 \\
& Posttest & 18 & 13 & 13 & 26 & 21.28 & 3.893 & -.586 & -.467 \\
\hline \multirow{2}{*}{ ISIG } & Pretest & 19 & 16 & 8 & 24 & 17.42 & 4.562 & -.376 & -.746 \\
& Posttest & 19 & 13 & 16 & 29 & 22.11 & 4.383 & .089 & -1.366 \\
\hline \multirow{2}{*}{ Control } & Pretest & 16 & 16 & 9 & 25 & 16.94 & 4.640 & .123 & -.839 \\
& Posttest & 16 & 16 & 11 & 27 & 18.56 & 4.830 & .262 & -1.083 \\
\hline
\end{tabular}

As shown in Table 1, the minimum pretest and posttest reading comprehension scores were 8,11 respectively which were below the median score (20) on a 40-point scale. The maximum pretest and posttest scores were 25 and 29 respectively which were above the median score (20). The skewness and kurtosis values were between -2 and +2 indicating that the distribution of all data sets was rather normal.

According to Table 1, the pretest reading comprehension mean scores were 18.69, 18.06, 17.42, and 16.94 in the FSIG, MSIG, ISIG and control group, respectively. That is, the pretest mean score in the FSIG was larger than those in the other groups. The posttest mean scores were 21.31, 21.28, 22.11, and 18.56 in the FSIG, MSIG, ISIG and control group, respectively, meaning that all the four groups showed an increase from the pretest to posttest to some extent; however, the greater amount of improvement belonged to the ISIG. Results related to the pretest and posttest mean scores are shown graphically in Figure 1 below. 


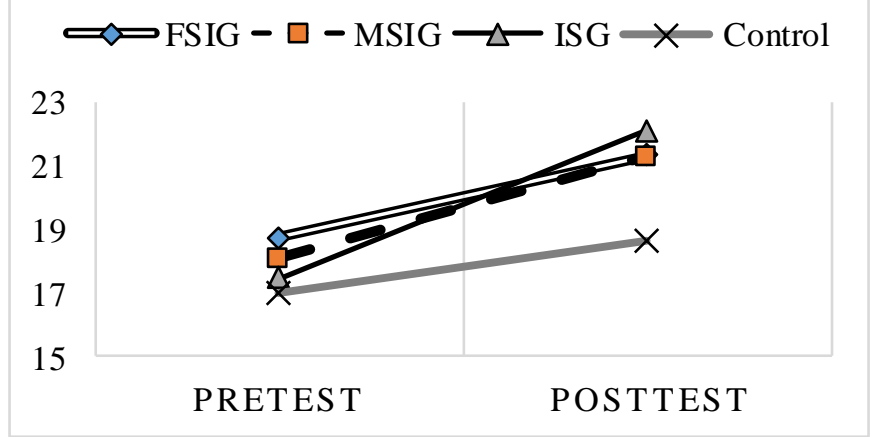

Figure 1. Pretest to posttest reading comprehension mean-score changes

As illustrated in Figure 1 the steep increase in the mean scores (from pretest to posttest) in the ISIG and MSIG in comparison with the gentle slope of the changes in the FSIG and the control group showed more improvement in their participants' ability of reading comprehension after receiving the treatments.

Table 2 displays the descriptive statistics of the pretest and posttest vocabulary scores in all four groups of the study.

\begin{tabular}{llllllllll}
\multicolumn{1}{l}{ Table 2. Descriptive Statistics of Vocabulary Scores } & & & \\
\hline \multirow{2}{*}{ Group } & Variable & $N$ & Range & Min & Max & Mean & $\begin{array}{l}\text { Std. } \\
\text { Deviation }\end{array}$ & Skewness & Kurtosis \\
& & & & & & & & & \\
\hline \multirow{2}{*}{ FSIG } & Pretest & 16 & 7 & 5 & 12 & 8.75 & 2.35 & -.114 & -1.453 \\
& Posttest & 16 & 8 & 5 & 13 & 9.87 & 2.47 & -.350 & -.863 \\
\hline \multirow{2}{*}{ MSIG } & Pretest & 18 & 7 & 6 & 13 & 9.61 & 1.94 & -.459 & -.229 \\
& Posttest & 18 & 6 & 7 & 13 & 10.72 & 1.77 & -.519 & -.534 \\
\hline \multirow{2}{*}{ ISIG } & Pretest & 19 & 8 & 5 & 13 & 9.00 & 2.28 & .031 & -.950 \\
& Posttest & 19 & 8 & 7 & 15 & 11.10 & 2.13 & .001 & -.489 \\
\hline \multirow{2}{*}{ Control } & Pretest & 16 & 7 & 6 & 13 & 8.62 & 2.28 & .764 & -.232 \\
& Posttest & 16 & 8 & 6 & 14 & 9.37 & 2.33 & .810 & .128 \\
\hline
\end{tabular}

As demonstrated in Table 2 the minimum pretest and posttest vocabulary score was 5 which was below the median score (10) on a 20-point scale. The maximum pretest and posttest scores were 13 and 15 respectively which were above the median score (10). The skewness and Kurtosis values in both groups were within +2 and -2 , indicating little clustering of the scores at the ends and a very small degree of flatness. According to Table 1, the pretest vocabulary mean scores were 8.75, 9.61, 9.00, and 8.62 in the FSIG, MSIG, ISIG and control group, respectively. That is, the pretest vocabulary mean score in the MSIG was larger than those in the other groups. The posttest mean scores were 9.87, 10.72, 11.10, and 9.37 in the FSIG, MSIG, ISIG and control group, respectively, indicating that all the four groups showed an increase from the pretest to posttest to some extent; however, the greater amount of improvement belonged to the ISIG. Figure 4.2 bellow demonstrate the changes from the pretest mean scores to the posttest as well as delayed posttest mean scores in all groups of the study.

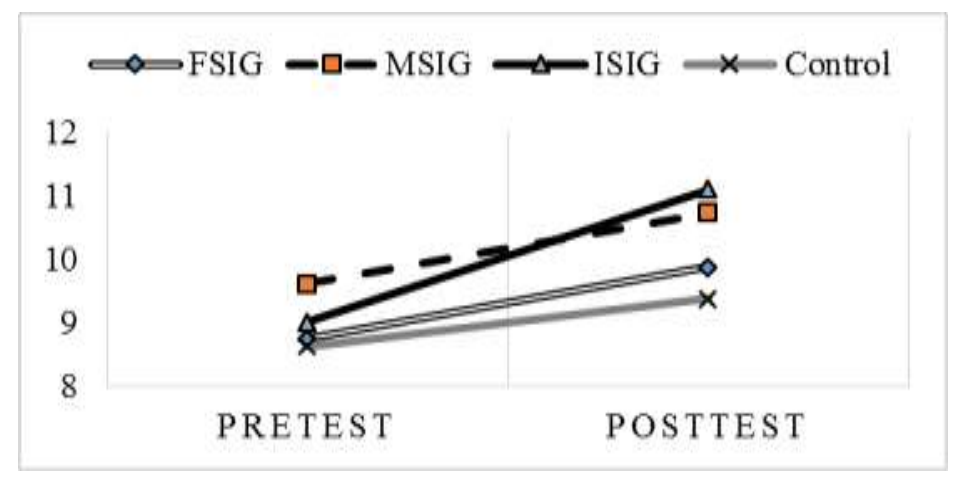

Figure 2. Pretest and posttest vocabulary mean scores' changes 
As shown in Figure 4.2, among all groups of the study, the highest amount of change from pretest to posttest belonged to the ISIG. The remarkably similar slope of the changes in the other three groups (FSIG, MSIG, and control group) indicates that the groups improved rather alike in terms of reading comprehension achievement.

The first research question intended to examine whether receiving either fixed or multiple instruction of comprehension strategies has any significant effects on reading comprehension ability of intermediate EFL learners. In addition, the second research question of the study aimed to explore if integration of fixed and multiple instructional techniques significantly improve Intermediate EFL learners' reading comprehension ability of intermediate EFL. To investigate these questions of the study, a one-way analysis of covariance (ANCOVA) was conducted to compare the posttest scores while controlling for pre-existing (pretest) differences among the groups. However, it was so important first, to make sure that the data can actually be analyzed using ANCOVA by checking the underlying assumptions.

In addition, before running an ANCOVA, it was important to make sure of homogeneity of regression slopes. In order to meet this assumption, an ANCOVA was conducted to see whether there was a significant interaction between different types of treatments (focused strategy intervention, multiple strategy intervention, integrated strategy intervention, and no intervention) and the pretest scores. The results are reported in Table 3 below.

Table 3. Analysis of Covariance for the Effects of instructions on Reading Comprehension

\begin{tabular}{llllll}
\hline Source & $\begin{array}{l}\text { Type III Sum of } \\
\text { Squares }\end{array}$ & $d f$ & Mean Square & $F$ & Sig. \\
\hline Corrected Model & $1257.756^{\mathrm{a}}$ & 7 & 179.679 & 82.214 & .000 \\
Intercept & 71.638 & 1 & 71.638 & 32.779 & .000 \\
Group* pretest scores & 4.815 & 3 & 1.605 & .734 & .535 \\
Group & 17.778 & 3 & 5.926 & 2.711 & .053 \\
Pretest scores & 1127.342 & 1 & 1127.342 & 515.826 & .000 \\
Error & 133.316 & 61 & 2.186 & & \\
Total & 31485.000 & 69 & & & \\
Corrected Total & 1391.072 & 68 & & & \\
\hline
\end{tabular}

a. $\mathrm{R}$ Squared $=.904$ (Adjusted R Squared $=.893$ )

The results in Table 4 show that the slope of the regression line in each group was similar and there was not any significant interaction between the treatment in different groups and the pretest scores $(F(3,61)=.734, p>.05)$. As Table 5 displays, there was a significant effect for the group variable representing the type of instruction indicating statistically significant posttest score differences across the groups, $F(3,64)=13.418, p<.005$ Moreover, the effect size value, shown by partial eta squared value in the above table, was .386. This value indicates that $38.6 \%$ of the variance in the dependent variable (posttest scores) was explained by the independent variable (different types of instruction). In other words, the differences between different groups' adjusted means were significant in terms of different types of instruction.

Table 4. Analysis of Covariance for the Effects of instructions on Reading Comprehension

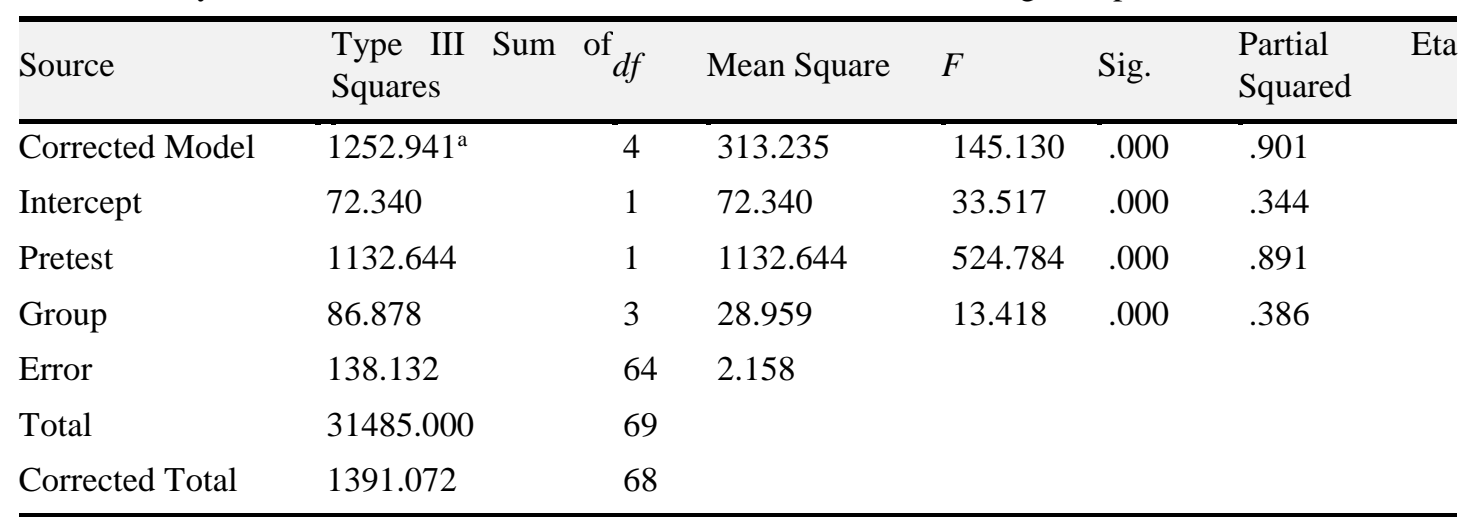

a. R Squared $=.901$ (Adjusted R Squared $=.894$ )

As Table 5 displays, there was significant difference between MSIG and the control group ( $p=.009)$; however, the difference between FSIG and the control group was found to be none-significant $(p=.215)$. In other words, the reading comprehension achievement of the intermediate EFL learners who benefited from multiple instructional techniques of comprehension strategies improved significantly compared to those who received instruction only on focused instructional techniques as well as those in the control group who received no strategic reading instruction. 
Accordingly, the first hypothesis of the study was rejected with regard to multiple strategy intervention but rejected regarding focused strategy intervention. It is worth mentioning that although the candidates in the MSIG on average outperformed those in the FSIG, the difference between these two groups' adjusted means was not statistically significant $(p=1.000)$

Table 5. Analysis of Covariance for the Effects of instructions on Reading Comprehension

\begin{tabular}{|c|c|c|c|c|c|c|}
\hline \multirow[b]{2}{*}{ (I) GROUP } & \multirow[b]{2}{*}{ (J) GROUP } & \multirow{2}{*}{$\begin{array}{l}\text { Mean Difference } \\
(\mathrm{I}-\mathrm{J})\end{array}$} & \multirow[b]{2}{*}{ Std. Error } & \multirow[b]{2}{*}{ Sig. ${ }^{b}$} & \multicolumn{2}{|c|}{$\begin{array}{l}\text { 95\% Confidence Interval for } \\
\text { Difference }^{b}\end{array}$} \\
\hline & & & & & Lower Bound & Upper Bound \\
\hline \multirow{3}{*}{ FSIG } & MSIG & -.552 & .505 & 1.000 & -1.929 & .824 \\
\hline & ISIG & $-1.969^{*}$ & .501 & .001 & -3.334 & -.605 \\
\hline & Control Group & 1.124 & .524 & .215 & -.303 & 2.551 \\
\hline \multirow{3}{*}{ MSIG } & FSIG & .552 & .505 & 1.000 & -.824 & 1.929 \\
\hline & ISIG & $-1.417^{*}$ & .484 & .028 & -2.735 & -.099 \\
\hline & Control Group & $1.676^{*}$ & .507 & .009 & .297 & 3.056 \\
\hline \multirow{3}{*}{ ISIG } & FSIG & $1.969^{*}$ & .501 & .001 & .605 & 3.334 \\
\hline & MSIG & $1.417^{*}$ & .484 & .028 & .099 & 2.735 \\
\hline & Control Group & $3.093^{*}$ & .499 & .000 & 1.735 & 4.452 \\
\hline \multirow{3}{*}{$\begin{array}{l}\text { Control } \\
\text { Group }\end{array}$} & FSIG & -1.124 & .524 & .215 & -2.551 & .303 \\
\hline & MSIG & $-1.676^{*}$ & .507 & .009 & -3.056 & -.297 \\
\hline & ISIG & $-3.093^{*}$ & .499 & .000 & -4.452 & -1.735 \\
\hline
\end{tabular}

The focus of inquiry in the third research question was to examine whether receiving either fixed or multiple instruction of comprehension strategies has any significant effects on lexical knowledge of intermediate EFL learners. Additionally, the fourth research question of the study intended to investigate if integration of fixed and multiple instructional techniques improve Intermediate EFL learners' lexical knowledge significantly. One-way analysis of covariance (ANCOVA) was conducted to compare the posttest vocabulary scores while controlling for pre-existing (pretest) differences among the groups.

\section{Discussion}

This study initially set out to investigate the impact of two reading strategies; namely, focused and multiple strategy instruction on L2 learners' reading comprehension and vocabulary achievement with those exposed to the mainstream reading instruction methodology. Then, it sought to explore whether integrating fixed and multiple instructional strategies could improve reading comprehension ability and lexical knowledge of Iranian intermediate EFL learners. To this end, the achievement of the targeted participants in four intact classes were compared in terms of the type of instruction they had received. Based on the analysis of the data presented in the previous section and the results thereof, the following significant findings were drawn:

- After controlling for between group initial differences, the participants' performance profiles on the posttest measures were found to be statistically significant in terms of both reading comprehension and vocabulary scores. Differently stated, applying different instructional techniques of reading strategies resulted in significant differences between groups' achievement after the treatment.

- Based on the results of the post hoc tests, the participants in all three experimental groups of the study (ISIG, MSIG, and FSIG) outperformed those of the control group in terms of both reading comprehension and vocabulary posttest scores; however, only the reading comprehension achievement of the learners who benefited from integrated strategy instruction (ISIG) as well as those who received instruction on multiple comprehension strategies (MSIG) were significantly more meaningful compared to those in the control group with no strategic reading training. Accordingly, it was revealed that receiving instruction on multiple comprehension strategies as well as benefiting from an integration of focused and multiple instructional techniques improved reading comprehension ability of the intermediate EFL learners. The participants of the FSIG who received focused instructional techniques improved in the same way as those trained by typical reading-based instruction in EFL contexts.

- With regard to lexical development, it was found out that integrated strategy instruction was the only instructional technique improving the lexical knowledge of the participants significantly compared to those in the control group. In other words, it was concluded that neither focused nor multiple instruction of comprehension strategies influenced the lexical knowledge of the intermediate EFL learners significantly 
more than those taught by the conventional method of reading in EFL contexts, whereas the integration of the said instructional techniques significantly improved lexical knowledge of the intermediate EFL learners.

- A Significant difference was also found between reading comprehension achievement of the learners who received multiple strategy intervention (MSIG) and those who benefited from focused strategy intervention; however, the amount of difference between the groups was not statistically significant in terms of lexical knowledge.

Based on the results obtained in the light of running different statistical tests, no significant difference was found between the FSIG and the control group in terms of posttest reading comprehension scores. One possible reason for this finding may be the fact that the strategies taught in the FSIG (inferencing and questioning) are the most ubiquitous procedures employed by material developers in designing the majority of exercises and activities utilized in reading course-books. Moreover, these strategies are usually widely used in most typical reading-based programs by related teachers.

As for the second hypothesis, a significant difference was found in posttest measures of comprehension between the MSIG and the control group indicating that those participants who received explicit instruction on a combination of comprehension strategies outperformed those of the control group significantly who participated in a traditional reading-based program since they did not receive any strategic reading instruction. Notably, the finding was consistent with the results attained by Cubukcu (2008) and Yee (2010).

In addition, the difference between the ISIG and all other groups (FSIG, MSIG, and control groups) was statistically significant indicating the efficacy of integrated strategy intervention in improving reading comprehension ability of the learners compared to typical reading-based instruction in EFL contexts. More specifically, the findings reflected the advantage of utilizing integrated instructional techniques over either focused or multiple instructional techniques. The significant difference between the ISIG who received an integration of focused and multiple instruction of reading comprehension strategies and the control group with no specific strategic training resulted in rejection of the second hypothesis of the study. The result was in line with writers such as Arpacioglu (2007) and Aghaie and Zhang (2012). Finally, it was found out that participants with strategy training (i.e., the ISIG, MSIG, and FSIG groups) outperformed those of the control group in terms of lexical knowledge, the integrated strategy intervention was the only instructional technique which significantly improved the lexical knowledge of the participants.

\section{Conclusion}

This study sought to find an efficient and practical method of implementing strategic reading instruction in EFL contexts focusing on three instructional methods; namely, focused, multiple, and integrated instruction of reading comprehension strategies. On the basis of the findings discussed above, it can be concluded that:

- Activating and exploiting metacognitive awareness of learners about a single comprehension strategy in EFL classrooms named focused-strategy instruction, does not represent a significant advantage over typical readingbased instruction in improving reading comprehension and lexical development of intermediate EFL learners. Full comprehension of a variety of texts developed based on a wide range of genres would demand utilizing different strategies.

- Receiving explicit instruction while hybridizing reading comprehension strategies including single-focused and multiple focused strategies can be effective in enhancing the rate of decoding and comprehending texts by Iranian intermediate EFL learner.

- Using an integration of fixed and multiple reading comprehension strategies explicitly would offer the advantages of both mixed and focused instructions. Consequently, integration may lead to a higher reading comprehension development as well as higher gains in lexical knowledge of Iranian intermediate EFL learners.

\section{References}

Aghaie, R., \& Zhang, L. J. (2012). Effects of explicit instruction in cognitive and metacognitive reading strategies on Iranian EFL students' reading performance and strategy transfer. Instructional Science, 40.6

Arpacioğlu, E. B. (2007). The effect of combined strategy instruction on reading comprehension. Unpublished master's thesis. Ankara: Bilkent University Graduate School of Education.

Baker, L., \& Brown, A. L. (1984). Metacognitive skills and reading. In P. D. Pearson (Ed.), Handbook for reading research. New York, NY: Longman, 353-394.

Biancarosa, C., \& Snow, C. (2006). Reading next-A vision for action and research in middle and high school literacy: A report to the Carnegie Corporation of New York (2nd Ed.). Washington, DC: Alliance for Excellent Education.

Brown, J. D. (1981). Understanding research in second language learning: A teacher's guide to statistics and research design. Cambridge University Press.

Caccamise, D., \& Snyder, L. (2005). Theory and Pedagogical Practices of Text Comprehension. Topics in language disorders, 25(1), 5-20.

Cain, K., \& Oakhill, J. V. (1999). Inference making ability and its relation to comprehension failure in young children. Reading and Writing: An Interdisciplinary Journal, 11(5-6), 489-503. 
Cubukcu, F. (2008). How to enhance reading comprehension through metacognitive strategies. The Journal of International Social Research, 1(2), 83-93.

DeBoer, S. R. (2003). Role of Explicit Teaching of Cognitive/Metacognitive Reading Strategies to Improve Reading Comprehension at the Elementary Level. Unpublished master's thesis. Dordt College Department of Education.

Duke, N. K., \& Pearson, P. D. (2002). Effective practices for developing reading comprehension. In A. E. Farstrup \& S. J. Samuels (Eds.), what research has to say about reading instruction (pp. 205-242), IRA, Newark, DE?

Duke, N. K., \& Pearson, P. D. (2002). Effective practices for developing reading comprehension. In A. E. Farstrup \& S. J. Samuels (Eds.), What research has to say about reading instruction (3rd edn., vol. 3). Newark, DE: International Reading Association, 205-242.

Duke, N. K., Pressley, M., \& Hilden, K. (2004). Difficulties with reading comprehension. In C. A. Stone, E. R. Silliman, B. J. Ehren, \& K. Apel (Eds.), Handbook of language and literacy development and disorder (pp. 501-520). New York: Guildford.

Fan, H. (2009). The effectiveness of metacognitive strategies in facilitating Taiwanese university learners in EFL reading comprehension. Ph.D. dissertation, University of Kansas.

Far, M. M. (2006). On the relationship between ESP \& EGP: A general perspective. English for Specific Purposes World, 7(1), 1-11.

Goldenberg, C. (2011). Reading instruction for English language learners. In M. L.

Grabe, W. (2002). Dilemmas for the development of second language reading abilities. Methodology in language teaching: An anthology of current practice, 276-286.

Grabe, W. (2009). Reading in a second language: Moving from theory to practice. New York, NY: Cambridge University Press.

Graesser, A. C. (2007). An introduction to strategic reading comprehension. In D. S. McNamara (ed.), Reading comprehension strategies: Theories, interventions, and technologies. Mahwah, NJ: Lawrence Erlbaum, 3-26.

Graves, M. (2004). Theories and constructs that have made a significant difference in adolescent literacy-but have the potential to produce still more positive benefits. In T. L. Jetton \& J.A. Dole (Eds.), Adolescent literacy research and practice (pp. 433-452). New York: The Guilford Press.

Janzen, J. (2003). Developing strategic readers in elementary school. Reading Psychology, 24.1, 25-55. doi: $10.1080 / 02702710390147016$.

Kazemi, M., Hosseini,M., \& Kohandani, M. (2013). Strategic Reading Instruction in EFL Contexts. Theory and Practice in Language Studies, 3(12), 2333-2342.

Krashen, S. D. (1989). Language acquisition and language education: Extensions and applications. Prentice Hall International.

Langer, J. A. (2002). Effective literacy instruction: Building successful reading and writing programs. Urbana, IL: National Council of Teachers of English.

Lee, L., \& Gundersen, E. (2000). Select Readings: Teacher-approved readings for today's students (2nd Ed.). New York: Oxford University Press.

McNamara, D. S. (2007). Reading comprehension strategies: Theories, interventions and technologies. Mahwah, NJ: Lawrence Erlbaum Associates.

McLaughlin, and Allen (2009) Guided Comprehension in Grades 3-8, and Revisit, Reflect, Retell by Hoyt (2009).

Nagy, W. E., Herman, P. A., \& Anderson, R. C. (1985). Learning words from context. Reading research quarterly, 233-253.

Nation, I. S. (2001). Learning vocabulary in another language. Ernst Klett Sprachen.

Nation K., \& Norbury, F. (2005). Why reading comprehension fails: Insights from developmental disorders. Topics in language disorders, 25, 21-32.

National Reading Panel (2000). Teaching children to read: An evidence-based assessment of the scientific research literature on reading and its implications for reading instruction: Reports of the subgroups. Bethesda, MD: National Institute of Child Health and Human Development, National Institutes of Health.

Nokes, J. D. \& Dole, J. A. (2004). Helping adolescent readers through explicit strategy instruction. In T. L. Jetton \& J. A. Dole (Eds.), Adolescent literacy research and practice (pp. 162-182). New York: The Guilford Press.

Phakiti, A. (2006). Theoretical and pedagogical issues in ESL/EFL teaching of strategic reading. University of Sydney Papers in TESOL, 1, 19-50.

Philips, D. (1996). Longman preparation course for the TOEFL test. London: Longman.

Pressley, M. (2006). Reading instruction that works: The case for balanced teaching ( $3^{\text {rd }}$ edn.). New York: The Guilford Press. 
Pressley, M. \& Afferbach, P. (1995). Verbal protocols of reading: The nature of constructively responsive reading. Hillsdale, NJ: Erlbaum.

Pressley, M., \& El-Dinary, P. B. (1997). What we know about translating comprehension strategies instruction research into practice. Journal of Learning Disabilities, 30, 486-488.

Read, J. (2000). Assessing vocabulary. Cambridge: Cambridge University Press.

Roe, M. F. (2008). The ways teachers do the things they do: Differentiation in middle level literacy classes. Middle Grades Research Journal, 5(3), 39-53.

Schmitt, N. (2000). Vocabulary learning strategies. Vocabulary: Description, acquisition and pedagogy, 199227.

K. Dickinson (Eds.), Handbook of early literacy research (pp. 173-182). New York: Guilford Press.

Shang, H. F. (2010). Reading strategy use, self-efficacy and EFL reading comprehension. Asian EFL Journal, 12(2), 18-42.

Sternberg, R. J. (1987). Our research program validating the tribrachic theory of successful intelligence: Reply to Gottfredson. Intelligence, 31(4), 399-413.

Swanson, D. R. (2001). Searching natural language text by computer. Science, 132(3434), 1099-1104.

Van Keer, H., \& Verhaeghe, J. P. (2005). Effects of explicit reading strategies instruction and peer tutoring on second and fifth graders' reading comprehension and self-efficacy perceptions. The Journal of Experimental Education, 73(4), 291-329.

Yee, N. (2010). Understanding reading comprehension: multiple and focused strategy interventions for struggling adolescent readers. Material thesis, University of Saskatchewan, Canada.

Williams, J. P. (2005). Instruction in reading comprehension for primary-grade students: A focus on text structure. Journal of Special Education, 39(1), 6-18. 